\title{
GENOCIDIO, CONCEPTO INVISIBILIZADO EN LOS LIBROS DE TEXTOS DE GEOGRAFÍA
}

\author{
María Cristina Nin ${ }^{1}$ \\ Departamento e Instituto de Geografía, \\ Facultad de Ciencias Humanas, \\ Universidad Nacional de La Pampa \\ Gil 353, $3^{\circ}$. 5300, Santa Rosa. La Pampa, Argentina \\ nincristina@gmail.com
}

\begin{abstract}
Resumen: En este trabajo se analizan propuestas editoriales de Geografía que están disponibles en Argentina para la enseñanza secundaria a escala mundial. El foco del análisis se realiza a partir de los procesos genocidas del siglo XX y XXI. Los textos escolares se constituyen en una herramienta y fuente de consulta para los estudiantes, pero su interpretación y el acceso al saber requieren de la mediación de los docentes. Desde el paradigma de una Geografía crítica, inspiradora de la defensa de los derechos humanos y comprometida con problemáticas relevantes para la sociedad, se presentan los resultados del análisis de libros de propuestas editoriales de geografía, y de entrevistas a profesores.
\end{abstract}

Palabras clave: Geografía, Enseñanza, Genocidios, Libros de textos, Profesores.

\begin{abstract}
This work analyzes the editorial proposals of Geography that are available in Argentina for secondary education worldwide. The focus of the analysis is carried out from the genocidal processes of the XX and XXI century. School texts are a tool and source of consultation for students, but their interpretation and access to knowledge require the mediation of teachers. From the paradigm of a critical Geography, inspiring the defense of human rights and committed to issues relevant to society, the results of the analysis of books on geography editorial proposals, and interviews with teachers are presented.
\end{abstract}

Keywords: Geography, Teaching, Genocides, Textbooks, Teachers.

Recibido: 27-07-2020. Aceptado: 21-09-2020.

1. Este artículo se enmarca en el Proyecto de Investigación "Geografía y enseñanza (De) construyendo teorías, prácticas, contextos y sujetos”. Aprobado por Resolución 042-18-CD-FCH-UNLPam. 
Padres, maestros, lideres políticos: todos debemos actuar con urgencia antes de que el odio encubierto se convierta en una abierta y alarmante normalidad. Las personas no nacen para odiar: la intolerancia se aprende y, por lo tanto, se puede prevenir y desaprender.

Guterrez, A. (2019)

\section{Introducción}

Concebir la educación desde la perspectiva de los derechos humanos es contemplar las dimensiones ética, cultural y política de éstos. Interpretarlos no solo como principios normativos que comparten los pueblos de diferentes latitudes, sino como una cultura de los derechos humanos. Es decir, si bien la Declaración Universal de los Derechos Humanos (DUDH) de 1948, vio su nacimiento en el mundo occidental, se puede pensar en marcos de referencia que contemplen la dignidad humana a escala global. Los derechos humanos son conquistas históricas que implican el esfuerzo y luchas por el respeto y dignidad humana individual y colectiva por una sociedad más libre e igualitaria. Los derechos humanos como conjunto de valores éticos, políticos occidentales están en permanente construcción. Este proceso está plagado de contradicciones ideológicas, avances, conquistas, es decir conflictos.

El acuerdo internacional en pos de la paz mundial vio la luz con la Declaración de 1948 en el contexto de las tragedias ocurridas durante la Segunda Guerra Mundial. Crueldades tales como campos de concentración, cámaras de gas, ciudades destruidas por bombas atómicas fueron cometidas por los países que luego firmaron la DUDH. Desde ese entonces a nuestros días hubo múltiples avances en materia de derechos humanos, se avanzó con otros acuerdos internacionales para defender derechos de los niños, de las mujeres, de los refugiados, entre otros. Sudáfrica vio el final del régimen del Apartheid, otras minorías excluidas accedieron a mayores tratos de igualdad. Sin embargo, en el mismo período, desde 1948 hasta la actualidad, en diferentes territorios del mundo se producen nuevas tragedias humanas provocadas por personas. Genocidios en Camboya en la década de los setenta, en Ruanda y Yugoslavia en los años noventa, regímenes dictatoriales en América Latina en los que desaparecieron miles de personas en los años setenta, así como persecuciones étnicas como el caso de los Rohinyás en Myanmar y el de los Yazidies en el norte de Irak, en la actualidad. Diversos territorios donde tienen lugar migraciones forzosas como consecuencia de los conflictos armados de alta intensidad. Inacción política ante miles de migrantes que pierden la vida en el Mar Mediterráneo, en el río Grande o en los desiertos intentando llegar a un territorio que les posibilite construir una vida digna. Por lo tanto, en este contexto internacional, resulta imprescindible pensar en la educación como la única herramienta para erradicar las violencias. Educación para formar ciudadanos democráticos y que de- 
fiendan y promuevan la paz. La formación en ciudadanía es uno de los elementos clave para trabajar en este propósito ya que la democracia es el camino para lograrlo.

Es por ello que resulta pertinente la investigación acerca de problemas de enseñanza que contemplen la paz, los derechos humanos, la justicia, la democracia, el ejercicio pleno de la ciudadanía y la responsabilidad social. El siglo XX se caracterizó por ser uno de los más crueles de la historia de la humanidad, dado que está marcado por dos guerras mundiales y genocidios desarrollados en distintos territorios. Por otra parte, también se destaca por una fructífera producción científica que, desde distintas perspectivas teóricas, abordan los escenarios de violencia y no respeto por la vida. Esta dicotomía es la que nos compromete como docentes e investigadores a instalar el debate en torno a la tensión que se produce en relación a los avances de la ciencia y la producción intelectual versus la destrucción de la vida humana. Explorar en la contradicción mencionada se convierte en una responsabilidad de los formadores de profesores.

La enseñanza enmarcada en una educación en derechos humanos se corresponde con el paradigma de la pedagogía crítica. En este sentido Kemmis (1993) afirma respecto de la ciencia crítica que para cambiar la educación, para comprenderla e interpretarla es necesario un proceso de transformación. Por su parte Giroux (1990) reflexiona acerca del rol de los profesores como intelectuales transformadores contra las diferentes formas de opresión de la sociedad. Es decir, el trabajo de los/as docentes tiene que articular la reflexión y la acción con el propósito de potenciar las habilidades y conocimientos de los estudiantes para que puedan intervenir en las injusticias como actores críticos. Desde esta perspectiva, la educación contribuye al empoderamiento social, es decir, al cambio personal y social. De este modo, favorece a formar sujetos activos, cooperativos y socialmente comprometidos. Este trabajo se enmarca en la investigación que realicé para la tesis de Doctorado en Geografía en la cual se plantea indagar el lugar que ocupa la enseñanza del concepto genocidio y las implicancias territoriales de este proceso y, por consiguiente, el rol de la enseñanza de la Geografía en la construcción de memoria. Se parte de la idea acerca de la relevancia de enseñar a partir de conceptos clave que permite sostener, a lo largo de una secuencia de enseñanza, la presencia de una idea transversal que constituye la llave para provocar aprendizajes relevantes y significativos. Éstos podrán contribuir a que los/as estudiantes interpreten la vida social con sus valores y contradicciones así como también, los contextos territoriales que la explican. La enseñanza del concepto de genocidio y sus implicancias, contribuirá a estimular en los estudiantes una conciencia ciudadana y posibilitará reconocerse como sujetos activos de la realidad caracterizada por tensiones y conflictos. Esta pedagogía problematizadora pondrá en juego los diferentes intereses y poderes comprometidos en la conformación de los contextos políticos, sociales y culturales de los que son parte los futuros docentes.

La Geografía, como ciencia social, contribuye a la construcción de ciudadanía. Sus herramientas teóricas y metodológicas brindan posibilidades para relacionar el pasado, el presente y la planificación del futuro, con conciencia histórica y geográfica. Es de- 
cir para defender los principios de justicia social y económica, así como la defensa de los derechos humanos, la igualdad de oportunidades, la inclusión de sectores marginados, el respeto y cuidado del ambiente, la construcción de memoria colectiva. En síntesis, la ciencia geográfica aporta a la formación de cultura democrática y a sujetos libres para tomar decisiones y adoptar resoluciones en situaciones que afectan a su propia vida y al entorno.

(...) la gran aportación de la geografía humanista es poner en tela de juicio muchos conceptos mal conocidos, ensanchar el campo de la disciplina sugiriendo nuevas vías que pueden ser esenciales, puesto que, como dice Relph, un estudio geográfico ha de medirse por "lo que añade al conocimiento del mundo o a nuestra propia comprensión", más que por seguir unas reglas metodológicas precisas (Estebánez, 1982, p. 27).

Los genocidios ocurridos en el siglo XX son un problema territorial y por lo tanto, compromete a los investigadores geógrafos a abordarlos. La Ley de Educación Nacional (2006) y el Programa "Educación y Memoria" (2006) habilitan a los/as profesores/as de todas las asignaturas a enseñar temáticas vinculadas con los derechos humanos y especialmente con los Genocidios del siglo XX. En este contexto histórico, de producción académica respecto a los problemas mencionados y también de cambios educativos resulta pertinente indagar la oferta editorial y su relación con la geografía escolar para comprender las prácticas de enseñanza de la geografía para la formación en ciudadanía. Tal como expresan "Todo esto tiene repercusiones en el modelo de ciudadanía que podemos construir a partir de la Geografía, permitiéndonos reflexionar en última instancia sobre la utilidad y necesidad social de esta disciplina" (Morón, Abril y Morón, 2019, p. 125).

En este trabajo se presenta el análisis de libros de textos de geografía en relación al concepto de genocidio. Se indagan las propuestas de lecturas y actividades para la escala mundial, este recorte se corresponde con los saberes que propone el curriculum de la Provincia de La Pampa, para el cuarto año de la educación secundaria ${ }^{3}$.

\section{Metodología}

La presente es una investigación educativa, y en este sentido, Carr y Kemmis consideran a este tipo de investigación como aquella que "(...) hace de la práctica una cosa

2. Un análisis más exhaustivo de este marco normativo se desarrolló en: Nin y Lorda (2019).

3. El curriculum de cuarto año de la educación secundaria de esta provincia se corresponde con los Núcleos de Aprendizaje Prioritarios que propone el Ministerio de Educación de la Nación. Es decir se aborda el estudio de Geografía a escala mundial. La secundaria está organizada en seis años, dos ciclos, uno Básico (de primero a tercer año) y otro Orientado (de Cuarto a sexto año) Los estudiantes de cuarto año tienen entre quince y dieciséis años de edad. 
más 'teórica' en el sentido de enriquecerla mediante la reflexión crítica, sin que por ello deje de ser 'práctica' por cuanto ayuda a formular más concluyentemente los juicios que informan la práctica educativa" (Carr y Kemmis, 2002, p. 20). Desde una perspectiva interpretativa se pretende, tal como plantea Imbernón (2002), analizar y comprender situaciones educativas para orientar la mejora del proceso de enseñanza y aprendizaje.

Se consultaron siete propuestas editoriales o libros de texto de enseñanza de la geografía que circulan en Argentina ${ }^{4}$. El trabajo de campo para indagar las prácticas de enseñanza en relación a la problemática planteada recopiló información a partir de entrevistas en profundidad a profesoras/es de nivel secundario. Desde una perspectiva interpretativa se intenta comprender los significados de los sujetos que intervienen en el hecho educativo (Bolívar, 2002). Tal como expresa Pagés:

A través de la enseñanza, el profesor transmite un modelo de sociedad y de persona en función de unos determinados valores; selecciona y ordena unos hechos, unos conceptos, unas teorías y unos procedimientos; plantea unas determinadas actividades con las cuales sus alumnos asimilarán los valores, los hechos y los conceptos, etc. (Pagés, 1998, pp. 212-213).

Analizar las prácticas de enseñanza es promover espacios de reflexión que posibiliten construir nuevas hipótesis, realizar diferentes interpretaciones y elaborar nuevos aportes teóricos. La investigación pretende que la teoría y la práctica dialoguen de manera permanente (Latorre, 2003). Las interpretaciones posibilitan pensar la mejora de las prácticas de enseñanza de la geografía. Es por ello que el análisis de los libros de texto se articula con entrevistas a profesores de enseñanza secundaria. Se realizaron nueve entrevistas en profundidad a profesores de cuarto año de la educación secundaria de la ciudad de Santa Rosa, La Pampa. La metodología cualitativa enriquece y sirve de fundamento a las nuevas perspectivas de la ciencia geográfica. Es desde la Geografía

4. Los profesores tienen libertad de elegir propuestas editoriales o de producir sus propios materiales. No existe en Argentina una directiva de señale cuál texto seleccionar. Sin embargo, el Ministerio de Educación de la Nación lleva adelante los procesos de selección y distribución de libros de texto, obras literarias y de consulta para niños, adolescentes, jóvenes y docentes de los niveles inicial, primario, secundario y de la formación docente. El propósito de estas acciones es garantizar la igualdad de oportunidades en el acceso a bienes culturales y acompañamos así las trayectorias escolares. "El proceso de selección tiene una doble instancia, nacional y provincial, cada una con funciones diferenciadas. La Comisión Asesora Nacional (CAN) revisa los textos en cuanto a su adecuación a los acuerdos federales curriculares, la ausencia de errores conceptuales y la calidad de la propuesta pedagógica didáctica. Por su parte, las Comisiones Asesoras Provinciales (CAP) analizan las obras según los diseños jurisdiccionales, los lineamientos de política educativa para el nivel y el ciclo así como la posibilidad de adecuarlos a las distintas realidades jurisdiccionales.

Los especialistas que efectúan la revisión de las obras presentadas en las convocatorias son seleccionados por las autoridades ministeriales de cada provincia. Sus antecedentes laborales y académicos son publicados y están sujetos a observaciones por parte de las editoriales" (https://www.argentina.gob.ar/educacion/ gestioneducativa/politicassocioeducativas/libros). 
social, que se pretende comprender los fenómenos sociales, desde la perspectiva de los actores o sujetos que participan de ellos. Hérin expresa respecto a la Geografía social francesa lo siguiente,

Esta geografía social se interesa prioritariamente por los hombres, por las sociedades, más que por los espacios, que ella considera que son producto de las sociedades. Inmersa en el mundo que vivimos, pretende ser a la vez científica e implicada en las cuestiones de la sociedad de nuestro tiempo. También es crítica tanto en el terreno científico como en el campo social (Hérin, 2006, p. 1).

La investigación en geografía social se sustenta en una actitud social crítica y en los principios universales de la racionalidad en la investigación y en valores universales que según Hérin deberían "regular las relaciones sociales: el respeto al ser humano; la igualdad de derechos, de deberes y de oportunidades, de donde proceden los principios de justicia y equidad; el respeto a las libertades individuales y colectivas (...); los principios de solidaridad" (Hérin, 2006, p. 28). Es desde esta perspectiva geográfica que se pretende contemplar las dimensiones que conforman las relaciones sociales en territorios en conflicto para contribuir al conocimiento de las relaciones de alteridad. En relación a la investigación en enseñanza de la Geografía, Souto (2013) expresa que investigar en educación refiere al proceso de reflexión de búsqueda sistemática a través de actividades intencionales para descubrir e intervenir en algo nuevo, esta intervención contribuiría a influir en la práctica del aula para mejorarla.

En este trabajo se analizan las propuestas editoriales a partir de los temas que proponen y se vinculan con el concepto de genocidio. A su vez se interrelacionan estos datos con la palabra de los docentes entrevistados con el propósito de elaborar reflexiones para la mejora de las prácticas de enseñanza.

\section{Los genocidios en clave territorial}

Los actores a través de sus acciones realizan transformaciones en los territorios a partir de las cuales se modifican las redes de relaciones multiescalares y las organizaciones y culturas locales. Los actores son productores de territorio, en forma material y simbólica. Sin embargo, cuando esta producción espacial se ve alterada por agentes externos con intereses contrapuestos a la sociedad local, se producen procesos violentos que destruyen la trama territorial, considerados procesos genocidas.

Una de las causas del inicio de procesos genocidas es no aceptar al "otro" como diferente, es rechazar la otredad. En la construcción de la alteridad, la espacialidad cumple un rol destacado y por lo tanto, la Geografía brinda herramientas para comprenderla. En esta línea de investigaciones se basa el enfoque postcolonial como intento de descolonizar la mente del etnocentrismo y del eurocentrismo (Albet y Benejam, 2000). 
Edward Said, autor de Orientalismo (1978) es uno de los representantes del postcolonilaismo ${ }^{5}$, su pensamiento es clave en la evolución de esta corriente teórica. En su obra plantea que oriente es una construcción de occidente, o sea europea, que la construcción de ese "otro" posibilitó construir la identidad europea. El autor sostiene que Oriente le sirvió a Europa -creadora de las colonias- para definir su imagen, su idea, su experiencia y, en este sentido, el orientalismo representa desde la mirada cultural e ideológica un discurso que se apoya en instituciones, enseñanzas, imágenes, y estilos coloniales (Said, 1991). Es así como "(...) el Otro es concebido como una entidad externa contra la que "nosotros" y "nuestra" identidad se moviliza, reacciona: además, en el encuentro colonial [...] el Otro vive más allá, en otro lugar: tiene, por tanto, una dimensión espacial inherente" (Albet y Benejam, 2000, p. 109). En esta línea teórica, se considera a la Geografía como la ciencia que puede indagar y comprender las múltiples causas de los conflictos que provocan procesos traumáticos y otorgar voz a las poblaciones afectadas para trabajar en la construcción de la paz.

Desde esta perspectiva, resulta pertinente la propuesta de Oslender (2018), quien propone el concepto "geografías del terror" 6 para pensar las violencias en diferentes territorios. Violencias que se convierten en cultura del miedo, la cual permite el control de las poblaciones que lo padecen.

"Las culturas del terror están basadas en el silencio y alimentadas por él. Sin duda, el deseo del torturador es también prosaico, adquirir información, actuar de acuerdo con las estrategias económicas a gran escala elaboradas por los amos y las exigencias de la producción" (Oslender, 2018, p. 78).

El autor propone un marco conceptual integrado por siete puntos para pensar las geografías del terror (Oslender, 2018). Ellos son:

- La producción de paisajes del miedo, son la huella del uso continuo del terror en una región. Luego del ataque a poblaciones civiles, tales como incendios de campos, viviendas, bombardeos, las marcas visibles se constituyen en estampas de los agentes del terror a su vez son recuerdos de los actos violentos y futura amenaza para los pobladores atemorizados. Estos paisajes se leen a través de las huellas que transforman el espacio en paisajes del miedo y manifiestan el terror como espectáculo, como estrategia comunicativa.

5. El postcolonialismo no es el período posterior al colonialismo, es un concepto que se refiere a la crítica social que intenta subvertir la perspectiva colonizadora y generadora de estereotipos occidentales. Es una corriente de pensamiento basada en un posicionamiento multidisciplinar.

6. Oslender propone el marco conceptual de las Geografías del Terror en base a su investigación del caso Colombiano. Sin embargo, abre la posibilidad de aplicarlo a otros territorios y otras realidades violentas. Su propuesta es "(...) una agenda para abordar el terror como un conjunto complejo de espacios, emociones, prácticas, movimientos y materialidades en una gama de escalas desde el cuerpo hasta las microgeografías de la casa, la calle, el río, el bosque y la región” (Oslender, 2018, p. 83). 
- Movilidad y prácticas espaciales rutinarias restringidas, que son impuestas por determinados regímenes autoritarios. Las restricciones pueden ser explícitas e impuestas por los agentes de control que impiden el desplazamiento de la población o implícitas impuestas por el miedo a desplazarse a ciertos lugares donde se verían amenazados. Este contexto de terror invade de un sentimiento de inseguridad que modifica los hábitos cotidianos de la población y el espacio se fragmenta. Esto puede llevar a la creación de campos de confinamiento tales como guetos o campamentos de refugiados.

- Transformación dramática del sentido de lugar, la dimensión subjetiva del sentido de lugar, los sentimientos hacia el mismo se modifican en contextos de violencia. Las personas sienten, piensan y hablan de diferentes maneras sobre sus lugares de vida que fueron impregnados de experiencias traumáticas, recuerdos y temor. El silencio suele ser la reacción de las poblaciones afectadas y atemorizadas.

- Desterritorialización, se produce cuando el desplazamiento físico y forzado de comunidades es provocado por amenazas, masacres y ataques. Hay una pérdida del control territorial de la población local, poblaciones enteras huyen de la violencia, abandonan sus tierras, sus casas. También existe la desterritorialización mental que es cuando las personas pierden el control territorial, restringen sus movimientos habituales, modifican sus rutinas y evaden los lugares que eran su espacio de vida.

- Movimientos físicos en el espacio, el desplazamiento forzado es la reacción a situaciones de amenaza y matanzas. Estos movimientos de población, que suelen ser masivos resultan en migraciones de corta duración y distancia o bien de muy prolongados períodos.

- Reterritorialización, es parte del proceso de desterritorialización, el retorno de las poblaciones desplazadas a su lugar de origen es el fin de la solución del conflicto. Este proceso es largo, complejo e implica redefiniciones en las relaciones sociales y una reconstrucción de los paisajes del miedo en espacios de solidaridad y paz. Los que no regresan, emprenden procesos de reterritorialización en otros espacios, donde se gesta la construcción de nuevas identidades.

- Estrategias espaciales de resistencia, brindadas por las posibilidades de movilizarse, de defenderse y de resistir a los actores violentos y confrontar al terror. La huida, el escape o el hecho de esconderse de los atacantes, pueden ser acciones de resistencia.

Este marco conceptual permite comprender tramas conflictivas muy complejas que afectaron y, aún hoy continúan provocando daños materiales y sociales a gran cantidad de seres humanos en diversos territorios. La ruptura de las territorialidades construidas socialmente es una de las consecuencias de los genocidios y habilita el estudio 
en clave territorial. Asimismo, es posible aplicar en la comprensión de los procesos genocidas los rasgos aportados por Oslender (2018) en lo que denomina las geografías del terror, dado que todas son acciones de los individuos que se transforman en estrategias sociales territorializadas.

\subsection{Propuestas editoriales y enseñanza de la Geografía}

Los libros de texto de enseñanza secundaria cumplieron y cumplen un rol preponderante en la planificación de los saberes a enseñar. Entre las funciones que realizan los libros de texto en el desarrollo curricular se distinguen, la realización de una determinada selección cultural, es decir que transmiten una determinada visión de la realidad, muchas veces tomada como legítima. Los libros son un producto de consumo, debido a que las editoriales funcionan como empresas y por lo tanto los textos son ofrecidos como productos de consumo. Y por último los libros de texto se convierten en el curriculum real ya que se utilizan como la propuesta que materializa el curriculum en todas sus dimensiones (Puelles, 2000; Torres, 1994; Braga y Belver, 2016). Los libros de texto deberían ser una herramienta y fuente de consulta de los/as estudiantes para que puedan acceder al saber con la mediación de sus docentes. Los saberes que se enseñan en Geografía forman visiones de la realidad en la que los jóvenes estudiantes tienen la oportunidad de reconocerse como actores partícipes de ella. Tal como expresa Pingel (2010), los libros de texto son uno de los aportes educativos más importantes, reflejan ideas básicas sobre una cultura nacional, y a menudo son un punto crítico de lucha cultural y controversia. Por lo tanto, como instrumentos escolares potentes en la enseñanza es necesario que se los mire bajo la lupa teórica y epistemológica crítica. Según Pagés, los libros de textos, manuales o propuestas editoriales son objetos "cargados de ideología, de contenidos, de imágenes, de actividades, de potencialidades educativas. (...) Un buen libro de texto, mal utilizado, puede no generar ni buenas enseñanzas ni buenos aprendizajes. Y contrariamente, un mal libro de texto, bien utilizado, puede generar excelentes aprendizajes" (Pagés, 2009, p. 2). Por su parte Martínez (2006a, p. 7) considera que "el problema del profesorado consiste en aplicar mecánica y técnicamente aquello que otros han pensado”. En otra publicación el autor propone:

La creatividad del maestro, la investigación didáctica, el compromiso militante con el cambio, la imaginación compartida entre equipos profesionales muy diversos, y el recorrido por la historia de la renovación pedagógica, nos pueden nutrir ahora de criterios, argumentos y estrategias prácticas muy potentes. Las llamadas nuevas tecnologías pueden contribuir a hacer todo esto mucho más fácil (Martínez, 2006b, p. 9).

En este sentido el rol de los profesores es fundamental en relación a la planificación de los ejes, conceptos, contenidos y recursos a utilizar en relación al curriculum vigente. En esta línea de análisis didáctico es relevante el concepto de recorte con- 
ceptual, como el modo de seleccionar la porción de la realidad territorial y la trama social que la conforma. Un recorte, tal como proponen Gojman y Segal (2005, p. 83) es "(...) la operación de separar, de aislar una parcela de la realidad coherente en sí misma, con una racionalidad propia, y a la que uno podría acercarse como si lo hiciera con una lente de aumento". Es decir, inicialmente el Ministerio de Educación de la Nación elabora en acuerdo federal, los Núcleos que se consideran prioritarios para la enseñanza de las ciencias sociales en la educación secundaria. Luego las provincias construyen su curriculum, y posteriormente en las instituciones educativas se plantean prioridades y acuerdos de área para pensar la enseñanza. De los sucesivos recortes mencionados, sin dudas el más sustantivo es el que decide el profesor/a, ya que lo hace en función de la perspectiva disciplinar con la que se formó y con el enfoque de enseñanza con el que acuerda o concibe el equipo de enseñanza de la institución a la que pertenece.

\subsection{Libros de texto y abordaje de genocidios a escala mundial}

De acuerdo a lo expresado en apartados anteriores, los genocidios destruyen la trama territorial de un grupo social y por lo tanto, los desplaza de su lugar de pertenencia, es decir de su patria. En los genocidios como el armenio, el Holocausto, el ruandés o el ocurrido en la ex Yugoslavia, hubo desplazamiento forzoso de miles de ciudadanos. Uno de los rasgos distintivos de los genocidios es la expulsión de las poblaciones de su lugar de residencia, por lo tanto el genocidio siempre implica el desplazamiento territorial. Tanto el exterminio como el desplazamiento son armas de destrucción del grupo y de su trama social. "Los genocidas generalmente apuntan tanto a destruir el poder de los grupos meta dentro de un territorio dado como a expulsar o quitarlos de ese territorio, ya sea simultánea o secuencialmente" (Shaw, 2013, p. 105). Con el propósito de indagar cómo se aborda este concepto en textos escolares de geografía, se consultaron siete libros de editoriales argentinas (Tabla 1) que contienen los saberes a enseñar en el cuarto año de la educación secundaria.

Los textos analizados desarrollan temáticas que podrían vincularse con el concepto genocidio, sin embargo éste no se presenta de manera explícita ni tampoco se organiza alguna secuencia didáctica que lo contemple. El tema de las migraciones forzadas en relación con las persecuciones políticas, étnicas o religiosas se aborda en todos los textos analizados (Tabla 1) pero no en el contexto geopolítico de los casos tipificados como genocidios. 
Tabla 1. Los temas vinculados al concepto de genocidio en los libros de texto

\begin{tabular}{|c|c|c|c|c|}
\hline Autores & $\begin{array}{l}\text { Año de } \\
\text { publicación }\end{array}$ & $\begin{array}{l}\text { Título } \\
\text { del libro }\end{array}$ & $\begin{array}{l}\text { Lugar } \\
\text { Editorial }\end{array}$ & $\begin{array}{l}\text { Temáticas vinculadas } \\
\text { a genocidios en } \\
\text { diferentes escalas }\end{array}$ \\
\hline $\begin{array}{l}\text { Claudia Barros } \\
\text { (Coordinadora) }\end{array}$ & 1999 & $\begin{array}{l}\text { Geografía. } \\
\text { La Organización } \\
\text { del espacio } \\
\text { Mundial }\end{array}$ & $\begin{array}{l}\text { Buenos Aires: } \\
\text { Estrada }\end{array}$ & $\begin{array}{l}\text { Cap, 8: La población en el } \\
\text { espacio: Xenofobia, } \\
\text { migraciones forzadas, } \\
\text { refugiados, limpieza étnica } \\
\text { en Yugoslavia. } \\
\text { Cap. 13: Los espacios urbanos: } \\
\text { Apartheid en Sudáfrica, } \\
\text { segregación urbana. } \\
\text { Cap. 15: El estado como unidad } \\
\text { político territorial. El destierro } \\
\text { del pueblo Saharahui. Nación } \\
\text { sin estado: el pueblo Kurdo. } \\
\text { En el caso de Kosovo. } \\
\text { Derechos Humanos y } \\
\text { Derecho Internacional. }\end{array}$ \\
\hline $\begin{array}{l}\text { Jorge Blanco, } \\
\text { Victoria Fernández } \\
\text { Caso y Raquel } \\
\text { Gurevich }\end{array}$ & 1999 & $\begin{array}{l}\text { Geografía Mundial } \\
\text { Contemporánea. } \\
\text { Los territorios de } \\
\text { la economía } \\
\text { globalizada }\end{array}$ & $\begin{array}{l}\text { Buenos Aires: } \\
\text { Aique }\end{array}$ & $\begin{array}{l}\text { Cap. 7: Estados y regiones: } \\
\text { distintas divisiones del mundo. } \\
\text { Formación del estado de Israel. } \\
\text { Éxodo de Palestinos. } \\
\text { Sudáfrica, apartheid. }\end{array}$ \\
\hline $\begin{array}{l}\text { Mariana Arzeno } \\
\text { y otros }\end{array}$ & 2007 & $\begin{array}{l}\text { Geografía Mundial } \\
\text { y los desafíos } \\
\text { del siglo XXI }\end{array}$ & $\begin{array}{l}\text { Buenos Aires: } \\
\text { Santillana }\end{array}$ & $\begin{array}{l}\text { Cap. 1: Estados y globalización: } \\
\text { Derecho Internacional. Corte } \\
\text { Internacional de Justicia. } \\
\text { Cap. 2: Cambios y conflictos } \\
\text { estatales: Armenia, un nuevo } \\
\text { estado con mucha historia. } \\
\text { Consecuencias de la guerra } \\
\text { en Ruanda. }\end{array}$ \\
\hline $\begin{array}{l}\text { Luis Domínguez } \\
\text { Roca, Silvia } \\
\text { Gonzáles y otros }\end{array}$ & 2015 & $\begin{array}{l}\text { Geografía. } \\
\text { Sociedad y } \\
\text { Economía en } \\
\text { el Mundo Actual }\end{array}$ & $\begin{array}{l}\text { Buenos Aires: } \\
\text { Estrada }\end{array}$ & $\begin{array}{l}\text { Cap. 2: Las Organizaciones } \\
\text { Internacionales. Corte } \\
\text { Internacional de Justicia. } \\
\text { Cap. 9: La Movilidad espacial } \\
\text { de la población. Migrantes } \\
\text { forzados, refugiados, desplazados } \\
\text { internos, desplazados por } \\
\text { conflictos políticos. }\end{array}$ \\
\hline
\end{tabular}




\begin{tabular}{|c|c|c|c|c|}
\hline Autores & $\begin{array}{l}\text { Año de } \\
\text { publicación }\end{array}$ & $\begin{array}{l}\text { Título } \\
\text { del libro }\end{array}$ & $\begin{array}{l}\text { Lugar } \\
\text { Editorial }\end{array}$ & $\begin{array}{l}\text { Temáticas vinculadas } \\
\text { a genocidios en } \\
\text { diferentes escalas }\end{array}$ \\
\hline $\begin{array}{l}\text { Soraya Ataide, } \\
\text { Rodolfo } \\
\text { Bertoncello y otros }\end{array}$ & 2017 & $\begin{array}{l}\text { Geografía. } \\
\text { El mundo y la } \\
\text { globalización }\end{array}$ & $\begin{array}{l}\text { Buenos Aires: } \\
\text { Santillana. } \\
\text { Saberes clave }\end{array}$ & $\begin{array}{l}\text { Cap. 2: Estados Nacionales, } \\
\text { territorios estatales: Disolución } \\
\text { de Yugoslavia. Mapa de } \\
\text { conflictos políticos. Guerras y } \\
\text { patrimonio de la humanidad. } \\
\text { Cap. 17: Las personas siguen } \\
\text { migrando: Guerras, } \\
\text { persecuciones políticas, } \\
\text { religiosas o culturales. } \\
\text { Migraciones forzadas. } \\
\text { Discursos xenófobos y racistas. }\end{array}$ \\
\hline $\begin{array}{l}\text { Viglieca, Martín } \\
\text { y otros }\end{array}$ & 2019 & $\begin{array}{l}\text { Geografía } 4 . \\
\text { Estados, } \\
\text { sociedades y } \\
\text { economía en el } \\
\text { mundo globalizado }\end{array}$ & $\begin{array}{l}\text { Buenos Aires: } \\
\text { Mandioca. } \\
\text { Serie Llaves }\end{array}$ & $\begin{array}{l}\text { Cap. 4: El desarrollo desigual } \\
\text { en el mundo: Guerra en Sudán. } \\
\text { Cap. 11: Las migraciones en el } \\
\text { mundo. Migraciones forzadas. } \\
\text { Causas políticas, persecuciones } \\
\text { por cuestiones étnicas o } \\
\text { religiosas, o por gobiernos } \\
\text { dictatoriales. Refugiados. } \\
\text { Apátridas. La población rohingyá. }\end{array}$ \\
\hline $\begin{array}{l}\text { Carolina García } \\
\text { (coordinadora) }\end{array}$ & 2019 & $\begin{array}{l}\text { Geografía } 4 . \\
\text { Sociedad y } \\
\text { economía en } \\
\text { el mundo } \\
\text { contemporáneo }\end{array}$ & $\begin{array}{l}\text { Buenos Aires: } \\
\text { Estrada }\end{array}$ & $\begin{array}{l}\text { Cap. 2: Los Organismos } \\
\text { internacionales. Los proyectos } \\
\text { de trabajo de la ONU. } \\
\text { Los problemas que aún no } \\
\text { puede resolver. } \\
\text { Cap. 9: La movilidad espacial } \\
\text { de la población. Forzados a } \\
\text { migrar. Desplazados internos. } \\
\text { Desplazados por conflictos } \\
\text { políticos internos. }\end{array}$ \\
\hline
\end{tabular}

Fuente: Elaborado por María Cristina Nin. 
El texto Geografía Mundial y los desafíos del siglo XXI del año 2007 cuenta con una sección denominada "Territorios en foco" en la que corresponde al capítulo 2 "Cambios y conflictos estatales". La lectura seleccionada "Armenia, un nuevo Estado con mucha historia" escrito por Marta Yousefian, menciona al genocidio de los armenios como el primero del siglo XX del siguiente modo:

(...) Armenia tuvo su mayor expansión durante el reinado de Tigrán II el Grande, cuando sus dominios abarcaban desde el mediterráneo hasta el Mar Caspio; desde el siglo XV Armenia estuvo dividida entre Turquía y Persia. A Partir del siglo XIX los armenios organizaron movimientos emancipatorios a los que Turquía respondió con matanzas y persecuciones. Se calcula que entre 1915 y 1923 fueron exterminados más de 1.500 .000 armenios, constituyendo el primer genocidio del siglo XX.

Luego de dos años de independencia, Armenia pasó, en 1920, a pertenecer a la Unión Soviética, hasta 1991, año de su desmembramiento. Desde entonces es un Estado soberano con un gobierno democrático (Arzeno et al., 2007, p. 23).

Esta sección está integrada por un mapa de Armenia y los países que la limitan, un pasaje que explica características de la población y la economía, y un breve texto denominado "más información" que dice,

Los armenios en la Argentina. La persecución y el genocidio provocaron la diáspora del pueblo armenio, es decir, muchos de ellos se instalaron en distintos lugares del mundo con el objetivo de rehacer sus vidas. En la Argentina, formaron una numerosa comunidad. En la actualidad, se estima que está integrada por alrededor de ciento veinte mil personas. Hay escuelas, templos, cetros culturales y deportivos (Arzeno et al., 2007, p. 23).

En el mismo capítulo se desarrolla la temática de varias naciones en un Estado y se presenta el conflicto de Ruanda. El análisis de las consecuencias del conflicto se complementa con el siguiente fragmento del Correo de la Unesco (2006);

Consecuencias de la guerra. "Desde hace más de diez años, Espérance Murorunkwere es comerciante en Kígali, la capital ruandesa. Esta mujer de unos cuarenta años, madre de cuatro hijos, vende productos de limpieza importados de Kenia. (...) Esperánce es una de las mujeres que consiguieron salir adelante en Ruanda, a doce años del genocidio que se saldó con casi 800.000 víctimas. (...) La guerra civil que sacudió al país en 1994 arcó un hito social, confirmado también por una realidad demográfica insoslayable: una vez sofocado el genocidio, el $70 \%$ de la población estaba constituido por mujeres. Agrupadas en asociaciones, tomaron a su cargo niños que el conflicto había dejado huérfanos. Asimismo se movilizaron en defensa de los derechos humanos y muchas se empeñaron en alfabetizar o promover el microcrédito" (Arzeno et al., 2007, p. 5). 
Este último texto presenta una de las problemáticas del genocidio, la situación de las mujeres solas, movilizadas en la defensa de los derechos humanos. Sin dudas habilita a seguir indagando y abre la posibilidad a instalar en el aula otros temas vinculados con los procesos genocidas. Si bien dos de los textos analizados (Tabla 1) se publicaron antes de la sanción de la Ley de Educación Nacional (LEN) y de la elaboración y propuesta del programa "Educación y Memoria" migración forzosa causada por persecuciones políticas, étnicas o religiosas estaban presentes pero sin referir a los genocidios que las precedieron. Es decir, estos temas propuestos habilitan a que el/la docente decida abordar en profundidad los casos mencionados, para ello sería necesario que el profesor/a elabore una secuencia con materiales que profundicen el genocidio de los armenios y el ocurrido en Ruanda.

Respecto a los textos publicados con posterioridad a la sanción de la LEN y de la propuesta del Ministerio de la Nación del Programa "Educación y Memoria", también trabajan temáticas relacionadas al proceso migratorio pos conflicto pero ninguno aborda la complejidad geopolítica de los procesos genocidas. Solo el texto publicado por Editorial Santillana (Arzeno, 2007) incorpora a través de diferentes fuentes complementarias el concepto "genocidio". La misma editorial publica en el año 2017 un texto actualizado en el cual no se aborda la temática.

Los libros de texto escolares son artefactos culturales que responden a un proyecto editorial y didáctico, a las ideas de los autores y por lo tanto representan a un proyecto político y educativo determinado. Se los puede considerar como curriculum sustituto del curriculum prescripto (Libedinsky, 2005). Las propuestas editoriales presentan un curriculum explícito y uno implícito, es por ello que el trabajo profesional de la docencia es imprescindible en la mediación de los saberes a enseñar, en la selección de los materiales de lectura y otros recursos, en la planificación de actividades que contemplen la realidad y los intereses de los/as estudiantes.

A pesar de las ausencias conceptuales que puedan presentar los textos escolares, es posible enseñar a leer e interpretar la realidad a partir de ellas. Pensarlas como oportunidad para indagar en la búsqueda y la interpretación de otras fuentes, documentos y recursos que permitan comprender procesos complejos como los genocidios. De este modo el uso del libro escolar puede convertirse en una transición hacia la consulta otros libros más sofisticados y a su vez, puede ser la posibilidad de conectarse con un libro completo, con su diagrama, colores, textos, paratextos, imágenes y aprender a leerlo

7. En un artículo previo se desarrollan las políticas educativas vinculadas a la enseñanza de temáticas que promuevan la construcción de la memoria y derechos humanos, Nin, M.C. y Lorda, M.A. (2019). Políticas educativas que propician la educación en memoria y derechos humanos. Rev. Univ. geogr. [online]. 2019, vol. 28, n. 1, pp. 135-153. Disponible en: <http://bibliotecadigital.uns.edu.ar/scielo.php?script=sci_arttext\&pid=S1852$42652019001100007 \& \operatorname{lng}=\mathrm{es} \& \mathrm{nrm}=\mathrm{iso}>$. 
con mirada crítica. Para estimular estas capacidades cognitivas el rol de los/as docentes es clave ya que tenemos la responsabilidad de instalar debates acerca de temáticas ausentes en el curriculum o en los textos escolares.

\subsection{La palabra de los docentes en relación al uso de libro de textos y la enseñanza de procesos genocidas}

La decisión del docente en cuanto a la selección de los materiales es fundamental en la planificación de las secuencias didácticas. La elección de un libro de texto para trabajar con estudiantes de secundaria debe complementarse con la selección de otras fuentes de lectura y la producción de materiales por parte de los docentes. Es importante que los/as estudiantes sepan leer un texto de manera completa y no que solo consulten fotocopias aisladas. No obstante, a partir del análisis de los textos seleccionados para el cuarto año, se desprende que el rol de los profesores es irremplazable al momento de planificar la enseñanza, de seleccionar ejes y conceptos y los materiales correspondientes. Respecto a su rol como profesionales de la enseñanza, los/as docentes entrevistados expresan,

El rol de los docentes es irremplazable. La autonomía de los estudiantes debe necesariamente ir acompañada de la guía del docente, pero también (y no se puede desdeñar este punto que creo que está en debate en los últimos años) entender también que el docente si bien no es el portador del conocimiento absoluto, si posee un bagaje crítico, denso (conceptualmente) y reflexivo absolutamente necesario para que los estudiantes construyan sus propios conocimientos. Un docente que no conoce su disciplina, ni las disciplinas relacionadas, tendrá menos instrumentos al momento de alcanzar aprendizajes significativos con sus estudiantes (E2).

En este nuevo contexto educativo, los docentes tenemos mayores desafíos al momento de planificar la enseñanza. Todo lo que buscamos tanto docentes como estudiantes está al alcance de nuestras manos con solo hacer un click en el celular. Los docentes tenemos la responsabilidad de otorgar orientaciones a los estudiantes de cómo acceder a determinados contenidos y no otros, de mostrarles una realidad diferente que no pueden encontrar en internet, ayudarlos a pensar y a reconocer procesos sociales que forman parte de nuestro pasado y de la historia reciente, de que son analíticos y críticos con lo que leen e investigan, que puedan tomar sus propias determinaciones y que sean autónomos. Tenemos grandes desafíos por delante, el docente es guía y organizador, el que posee la creatividad y el saber, el que toma decisiones al momento de seleccionar ante un currículum qué problemáticas selecciona para su abordaje en el aula (E3). 
Existen muchas propuestas novedosas para plantear en las aulas, con nuevos perfiles de alumnos. El enciclopedismo, memorístico y rutinario con seguridad ya no es el camino. Pero creo que habría que generar un cambio estructural en el sistema, donde efectivamente podamos emplear la diversidad de recursos que disponemos. La imposibilidad de trabajar con recursos tecnológicos en las aulas, con la cantidad de videos cortos, películas, mapas dinámicos con colores, mapas creativos, hacen que muchas de nuestras clases sean monótonas, inclusive para nosotros mismos. Estamos ante una nueva generación, donde tenemos la obligación de ser parte de ella por lo menos mientras estemos en el ejercicio docente, si es que pregonamos una mejor calidad educativa (E6).

Es fundamental ya que permiten que los estudiantes construyan sus conocimientos en un mundo complejo, cambiante y con gran cantidad y variedad de información al alcance de la mano. Pero a la vez es necesario generar herramientas que permitan analizar críticamente para actuar como futuros ciudadanos participativos y reflexivos (E4).

Los/as docentes tenemos el reto de facilitar secuencias de enseñanza que estimulen el pensamiento crítico y a su vez, facilitar materiales que les permitan descubrir realidades complejas, los actores sociales que las integran, las problemáticas y los conflictos de los que son parte. Sin embargo el mayor desafío es formar en capacidades que les permitan interpretar las fuentes que a diario les invaden, tales como las que visualizan en redes sociales o medios de comunicación. En tal sentido los docentes entrevistados expresan,

El rol de los docentes es fomentar el pensamiento crítico y reflexivo, independientemente de la disciplina a la cual se refiera. El "¿para qué?” nunca fue tan necesario como lo es en esta era de globalización, inmediatez y accesos directos. El avance en las comunicaciones y más aún con los múltiples formatos de acceso a la información hace necesaria la persistencia del docente en ser formadores de ciudadanos pensantes. Sería erróneo afirmar que todo el mundo tiene acceso a la información del ciberespacio, pero sí cada día más personas pueden lograr este acercamiento. Esto no significa comprensión de procesos, hechos, contenidos, etc; solo implica "poseer información", no comprenderla. Aquí es donde ingresa el rol docente como ordenador de la información, como facilitador de accesos, como orientador de contenidos, como promotor del pensamiento crítico (E5).

Desde mi experiencia como docente en diversas escuelas secundarias, entiendo que debemos dar respuestas a la realidad de las nuevas generaciones mediando responsabilidades compartidas y en consecuencia poder otorgar más y mejores herramientas en base a sus condiciones y necesidades formativas. Para ello, nuestra tarea de pensar qué y cómo enseñar cobra importancia a la hora de implementar propuestas de enseñanza relevante y actual en función con el contexto educativo actual (E1). 
Nosotros tenemos que actuar como nexos entre ese saber, como facilitadores de herramientas para que los y las estudiantes puedan adquirir el mismo y poder construir su propio aprendizaje.

El docente es guía en ese camino del aprendizaje pero también es sostén, transformador de la realidad; de esas frustraciones o logros que el niño o la niña pueda adquirir a lo largo del camino (E7).

Tal como expresan los/as profesores en Geografía entrevistados, la tarea de los/as docentes es, estimular el pensamiento crítico, cuestionar la realidad, buscar explicaciones a los conflictos, pensar y proponer soluciones para que los jóvenes estudiantes encuentren sentido a la Geografía y se sientan como actores activos, miembros de la sociedad. Vale decir que la selección de los libros escolares debe realizarse de manera responsable y crítica, por otra parte el libro seleccionado no constituye una competencia ni en modo alguno reemplaza la tarea docente.

Respecto a la enseñanza del concepto genocidio y su inserción en los saberes geográficos los docentes entrevistados lo consideran un tema complejo, poco estudiado en la formación y sus propuestas se expresan del siguiente modo:

Su abordaje exige la articulación interdisciplinar para facilitar diferentes aportes y perspectivas en discusión que ayuden a los y las estudiantes a construir un aprendizaje significativo desde múltiples miradas. A su vez, enriquece la formación profesional de los y las docentes involucrados pero no siempre se hace posible este trabajo, ya que implica compromiso, responsabilidad y tiempos al momento de acordar su tratamiento escolar. Así como también a nivel institucional (E. 1).

La interdisciplinariedad es la mejor herramienta de abordaje (E. 5).

Es necesario trabajar el concepto de genocidio de manera interdisciplinaria, dada la complejidad del tema y sus múltiples aristas. Para alcanzar la comprensión del proceso de los genocidios, hace falta la articulación de conocimientos territoriales, históricos, culturales, jurídicos, sociológicos, entre otros, que ameritan, un trabajo integrado y con una sólida propuesta pedagógica que acompañe el proceso de construcción de conocimientos en los estudiantes. (E.2).

Para la enseñanza de problemática de los genocidios sería trascendental su abordaje de modo articulado e interdisciplinario en este caso desde abordajes jurídicos, sociológicos, geográficos, históricos, ciudadanos. En este sentido, la normativa nacional como la Res. №93/09 del Consejo Federal de Educación (CFE) posibilita romper con la enseñanza tradicional por disciplina e invita a los docentes a pensar otros modos de organizar el aula y la enseñanza de ciertos temas transversales. Por un lado, posibilita el trabajo colaborativo y permite profundizar esta problemática sobre la base de las mismas categorías conceptuales como Derechos Humanos, Memoria, Ciudadanía democrática, entre otros conceptos propios de las ciencias sociales. La riqueza del trabajo compartido sin dudas resultará significativo tanto para los docentes como los estudiantes (E. 3). 
La problemática de los genocidios es posible abordarla a través de un trabajo articulado desde Historia, Formación ética y ciudadana y Lengua por ejemplo donde cada una puede aportar información, recursos y diferentes estrategias para ser planteado (E. 9).

Tal como se puede apreciar, los profesores/as entrevistados reconocen el desafío que es planificar la enseñanza de un concepto complejo, la mayoría acuerda en que el mayor reto es el trabajo interdisciplinario. Es decir la organización de secuencias didácticas compartidas con asignaturas como historia, construcción de ciudadanía o lengua. Debido a que las problemáticas de la sociedad no se encuentran organizadas en compartimentos separados, el abordaje integrado de los mismos sería lo más conveniente. Sin embargo en la organización escolar prima la división en asignaturas, es por ello que los profesores lo consideran un desafío, pedagógico, institucional y profesional. También valoran como positiva la normativa nacional que habilita a las instituciones educativas a proponer organizaciones de propuestas de enseñanza que contemplen el trabajo de articulación de las asignaturas.

Según Oller y Santisteban (2011) la formación de jóvenes para el ejercicio de la ciudadanía implica estimular el desarrollo de capacidades cognitivas, afectivas, sociales y morales. Pilar Benejam en su último libro publicado ¿Qué educación queremos? (2015), se pregunta también ¿para qué sociedad? y postula: para el reconocimiento de la dignidad humana, para defender la igualdad, para desarrollar la propia personalidad, para practicar la convivencia basada en la responsabilidad y la participación democrática. Es así que, los profesores tienen el desafío de convertirse en los creadores de su propio curriculum, de ofrecer oportunidades de explorar nuevos conceptos que anudan problemáticas complejas para instalar en las aulas la capacidad de comprender el mundo y transformarlo en un sitio mejor. Concebir la educación desde la perspectiva de los derechos humanos es contemplar las dimensiones ética, cultural y política de éstos. Interpretarlos no solo como principios normativos que comparten los pueblos de diferentes latitudes, sino como una cultura de los derechos humanos.

Las transformaciones en la sociedad ocurrirán con prácticas pedagógicas pertinentes a la formación de sujetos libres de pensamiento y respetuosos de las ideas del otro. Por ello desde la enseñanza hay que ofrecer herramientas para que cada estudiante pueda construir su propia subjetividad y de este modo, desarrolle capacidades que le permitan comprender el mundo y transformarlo. Se trata de considerar a los jóvenes estudiantes como ciudadanos de pleno derecho y, por lo tanto, actores socioespaciales que tienen voz y que mediante sus acciones presentes y futuras se apropiarán del espacio de manera individual, social y política. Individual porque se trata de una experiencia única y propia de cada persona; social porque las decisiones se toman en un contexto de relaciones interpersonales, de ahí que se considere al espacio como construido por sus relaciones (Santos, 1996; Massey, 2005). Y también política porque cada decisión que se tome, al expresar la manera de cómo utilizar el espacio se trata de un acto político (Malatesta y Granados, 2017). 


\section{Reflexiones}

A partir de las ideas esbozadas cabe preguntarse ¿cuán significativo y relevante es la enseñanza de los genocidios ocurridos en el siglo XX y XXI? ¿Estarán los adolescentes, estudiantes de secundaria, interesados en abordar procesos traumáticos de la naturaleza de las ocurridas en contextos genocidas? Es en este punto donde el docente cumple un rol relevante en la planificación de la enseñanza. Despertar el interés por temáticas complejas, desde la perspectiva de los derechos humanos, para que puedan pensarse ellos mismos como sujetos de derecho es uno de los ejes vertebradores de la formación en ciudadanía.

El marco conceptual desarrollado en las páginas precedentes, anclado en una Geografía comprometida con los más desfavorecidos, los invisibles o invisibilizados, permite pensar las causas de los conflictos, comprender los paisajes del terror, y las formas con que los afectados enfrentan esos miedos a través de estrategias de resistencia. En 1995 Tim Unwin expresaba en su libro El lugar de la Geografía, que una de "(...) las características más sobresalientes de la práctica geográfica de los últimos veinte años es que los geógrafos han aceptado cada vez más la diversidad inherente a la disciplina y han renunciado, por lo general, a intentar identificar un núcleo único" (Unwin, 1995, p. 259). El autor invita a desarrollar estas ideas tanto en la investigación como en la enseñanza, expresa que "(...) es necesario forjar una nueva identidad para la disciplina y situarla con firmeza dentro de la sociedad contemporánea de la que forma parte" (Unwin, 1995, p262). Entonces si se pretende practicar una verdadera geografía social y crítica para los problemas del siglo XXI, las investigaciones y sus aportes tienen que intentar comprender las problemáticas que afectan a las sociedades, darlas a conocer, para que se intente su superación. Centrar la mirada y hacer foco en problemáticas invisibilizadas para la mayoría de la sociedad pero que afectan de manera aterradora a otra parte de la misma, es practicar una Geografía comprometida.

Dar luz a procesos traumáticos y ponerlos a consideración de la comunidad académica y educativa, es contribuir a construir un mundo con menos desigualdades, carencias, violencias, en síntesis es aportar conocimiento para cimentar una ciudadanía plena de derechos. De este modo, desde el territorio de las aulas estaremos contribuyendo a construir futuros más equitativos. La geografía tiene mucho por aportar. Son los/as profesores los generadores de los procesos de innovación en la enseñanza, por lo tanto, también estimulan cambios culturales y son los hacedores de la implementación de las propuestas curriculares.

El docente como actor político y agente del Estado, participa en decisiones curriculares cuando planifica, gestiona su clase e interviene en la elaboración del proyecto institucional, por tal motivo es necesario que se apropie de los marcos normativos tanto políticos nacionales como provinciales. En este período de crisis social e incertidumbres, orientar la enseñanza de la Geografía como ciencia explicativa e interpretativa re- 
quiere de la actitud crítica y reflexiva del docente, que favorezca la selección y secuenciación de saberes fundamentados desde posturas epistemológicas, que movilicen el pensamiento crítico y autónomo. La selección de conceptos clave, como el propuesto en el presente artículo, posibilita la elaboración de tramas explicativas complejas ya que requieren de la articulación de múltiples dimensiones de análisis. En este sentido, la labor de la docencia corregirá las ausencias conceptuales tanto del curriculum como de las propuestas editoriales.

La relación entre experiencias de investigación y prácticas de enseñanza, fortalece la puesta en marcha de un proceso de reflexión en tanto se puedan desarrollar instancias de planificación, acción y reflexión de éstas prácticas. El proceso de transformación de la enseñanza no se lleva a cabo en soledad, individualmente, sino por el contrario en un ámbito de construcción colectiva, con el firme propósito de mejorar y renovar las tareas que nos convocan en la cotidianeidad de las aulas. La investigación de problemáticas socialmente relevantes, su abordaje, las fuentes que conforman su trama explicativa y los modos cómo los/as docentes piensan su enseñanza contribuye a reflexionar y realizar propuestas superadoras que instalen el diálogo entre la teoría y la práctica.

\section{Bibliografía}

Adamoli, M.C. (2014). Holocausto y genocidios del siglo XX: Preguntas, respuestas y propuestas para su enseñanza. Buenos Aires: Ministerio de Educación de la Nación.

Albet, A y Benejam, P. (2000). Una Geografía Humana renovada: Lugares y Regiones en un mundo Global. Barcelona: Vicens Vives.

Arzeno, M., Castro, H., García, P., Minvielle, S., Tagliavini, G. y Zibecchi, C. (2007). Geografĩa Mundial y los desafios del siglo XXI. Buenos Aires: Santillana.

Ataide, S., García, P. y Palacios, N. (2017). Geografía. El mundo y la globalización. Recursos para el docente. Buenos Aires: Santillana.

Barros, C. (Coord.) (1999). Geografía. La Organización del espacio Mundial. Buenos Aires: Estrada.

Benejam, P. (2015). ¿Qué educación Queremos?. Barcelona: Octaedro.

Blanco, M. (2001). La dimensión ideológica de los libros de texto. Kikiriki, 61, pp. 50-56.

Bolívar, A. (2002). “¿De nobis ipsis silemus?”: Epistemología de la investigación biográfico-narrativa en educación. Revista Electrónica de Investigación Educativa, 4 (1). Recuperado de http://redie.uabc.mx/redie/article/viewFile/49/91

Braga, G. y Belver, J.L. (2016). El análisis de libros de texto: una estrategia metodológica en la formación de los profesionales de la educación. Revista Complutense de Educación, 27 (1), pp. 199-218. DOI: https://doi.org/10.5209/rev_RCED.2016.v27.n1.45688

Campanario, J.M. (2001). ¿Qué puede hacer un profesor como tú o un alumno como el tuyo con un libro de texto como éste? Una relación de actividades poco convencionales. Enseñanza de las ciencias: revista de investigación y experiencias didácticas, 19 (3), pp. 351-64. Recuperado de https://www.raco.cat/index.php/Ensenanza/article/view/21753 
De Miguel, R. (2013). Geoinformación e innovación en la enseñanza-aprendizaje de la geografía: un reto pendiente en los libros de texto de secundaria. Didáctica de las Ciencias Experimentales y Sociales, 27, pp. 67-90. Recuperado de: https://core.ac.uk/download/pdf/71022952.pdf

Domínguez, L, González, S., García, G., Quetgles, R., Apaolaza, R., Maraschio, F. y Sosa, M. (2015). Geografía. Sociedad y Economía en el Mundo Actual. Buenos Aires: Estrada.

Estébanez, J. (1982). La Geografía Humanística. Anales de Geografía de la Universidad Complutense, 2, pp. 11-31. Recuperado de https://revistas.ucm.es/index.php/AGUC/article/viewFile/ AGUC8282110011A/32153

Giroux, H. (1990). Los profesores como intelectuales. Hacia una pedagogía crítica de los aprendizajes. Barcelona: Paidós.

Gojman, S. y Segal, A. (2005). Selección de contenidos y estrategias didácticas en ciencias sociales: La "trastienda" de una propuesta. En: Aisenberg, B. y Alderoqui, S. (2005). Didáctica de las Ciencias Sociales II. Teorías con prácticas. (pp. 77-100). Buenos Aires: Paidós.

Gutierrez, A. (2019). Discurso pronunciado el 7/11/2019 en ocasión del aniversario de la "Noche de los cristales rotos". Recuperado de news.un.org/es/story/2019/11/1465111

Hérin, R. (2006). Por una geografía social, crítica y comprometida. Scripta Nova. Revista electrónica de geografía y ciencias sociales, X (218). Recuperado de http://www.ub.es/geocrit/sn/sn218-93.htm

Imbernón, F. (Coord.) (2002). La investigación educativa como herramienta de formación del profesorado. Barcelona: Graó.

Kemmis, S. (1993). El curriculum más allá de la reproducción. Madrid: Morata.

Latorre, A. (2003). La investigación acción. Conocer y cambiar la práctica Educativa. Barcelona: Graó.

Libedinsky, M. (2005). Hacia una lectura comprensiva de los libros escolares. En: Litwin, E. (Comps.), Tecnología Educativa. Políticas historias, propuestas. (pp. 203-230). Buenos Aires: Paidós.

Malatesta, S. y Granados, J. (2017). La contribución de la geografía de los niños y de las niñas a la enseñanza de la geografía. Documents d'Análisi Geográfica, 63 (3), pp. 631-640. DOI: https://doi.org/10.5565/rev/dag.483

Martínez, J. (2006a). El libre de text en la societat de la información. Perspectiva Escolar, 302, pp. 2-12. Recuperado de https://www.rosasensat.org/revista/us-i-abus-del-llibre-de-text/

Martínez, J. (2006b). ¿De qué hablamos cuando hablamos de los libros de texto?. Ministerio de Educación Seminario Internacional de Textos Escolares Santiago de Chile, 19, pp. 1-9. Recuperado de https://www.uv.es/bonafe/documents/libros\%20texto.pdf

Massey, D. (2005). La filosofía y la política de la espacialidad: algunas consideraciones. En: Arfuch, L. (Comps.), Pensar este tiempo. Espacios, afectos, pertenencias. (pp. 101-128). Buenos Aires: Paidós.

Ministerio de Educación de la Nación. (2006). Ley de Educación Nacional № 26206.

Ministerio de Educación de la Nación. (2006). Programa "Educación y Memoria”. Recuperado de http://www.me.gov.ar/educacionymemoria/ 
Morón, M.C., Abril, D. y Morón, H. (2019). La Geografía Escolar a través de los libros de $3^{\circ}$ de Eso. Una comparativa entre Loe y Lomce. En: Macía, X.C., Armas, F.X. y Rodríguez, F. (Comps.), La reconfiguración del medio rural en la sociedad de la información. Nuevos desafios en la educación geográfica. (pp. 125-138). Santiago de Compostela: Andavira.

Nin, M.C. y Lorda, M.A. (2019). Políticas educativas que propician la educación en memoria y derechos humanos. Revista Universitaria de Geografía, Bahía Blanca, 28 (1). Recuperado de http://bibliotecadigital.uns.edu.ar/scielo.php?script=sci_arttext\&pid=S1852-4265201900 $1100007 \& \operatorname{lng}=\mathrm{es} \& \mathrm{nrm}=\mathrm{iso}$

Oller, M. y Santisteban, A. (2011). Valores democráticos y Educación para la ciudadanía. En: Santisteban, A y Pagés, J. (Eds.), Didáctica del conocimiento del Medio Social y Cultural en la educación Primaria. Madrid: Síntesis.

Oslender, U. (2018). Terror y geografía: examinar múltiples espacialidades en un mundo "aterrorizado". Clepsidra. Revista interdisciplinaria de Estudios sobre Memoria, 5 (9), pp. 68-85. Recuperado de http://ppct.caicyt.gov.ar/index.php/clepsidra/article/view/OSLENDER

Pagés, J. (1998). Líneas de investigación en didácticas de las Ciencias Sociales. En: Benejam, p. y Pagés, J. Enseñary aprender Ciencias Sociales, Geografía e Historia en la Educación Secundaria. Barcelona: Horsori.

Pagés, J. (2009). Los libros de texto de ciencias sociales, geografía e historia y el desarrollo de competencias ciudadanas. Textos escolares de historia y ciencias sociales, Seminario Internacional 2008, pp. 24-56. Ministerio de Educación de Chile: Santiago de Chile.

Pingel, F. (2010). UNESCO Guidebook on Textbook Research and Textbook Revision (2a revised and updated edition). Paris: UNESCO y Georg Eckert Institute for International Textbook Research. Recuperado de https://unesdoc.unesco.org/ark:/48223/pf0000117188

Puelles, M. (2000). Los manuales escolares: un nuevo campo de conocimiento. Historia de la Educación. Revista Interuniversitaria, (19), pp. 5-12.

Said, E. (1991). Orientalismo. Madrid: Ediciones Libertarias.

Santos, M. (1996). Metamorfosis del Espacio Habitado. Barcelona: Oikos Tau.

Shaw, M. (2013). ¿Qué es el genocidio?. Buenos Aires: Prometeo.

Souto, X. M. (2013). Investigación e Innovación Educativa: el caso de la Geografía escolar. Scripta Nova. Revista Electrónica de Geografia y Ciencias Sociales, XVII (459), pp. 1-36. Recuperado de http://www.ub.edu/geocrit/sn/sn-459.htm

Torres, J. (1994). Globalización e interdisciplinariedad: el curriculum integrado. Madrid: Morata.

Unwin, T. (1995). El Lugar de la Geografía. Madrid: Cátedra.

Vera, A.L. y de Lázaro, M.L. (2011). La enseñanza de la geografía en bachillerato a partir del análisis de los libros de texto. Didáctica Geográfica, 11, pp. 169-197. Recuperado de https://didacticageografica.age-geografia.es/index.php/didacticageografica/article/view/45 